\title{
Current Trends, Challenges and Opportunities of Selected Digital Libraries in Ethiopia
}

\author{
Getachew Gedamu \\ Department of Information \\ Science \\ University of Gondar, Ethiopia
}

\author{
Alehegn Adane \\ Department of Information \\ Science \\ University of Gondar, Ethiopia
}

\author{
Assefa Chekole \\ Department of Information \\ Science \\ University of Gondar, Ethiopia
}

\begin{abstract}
This study explores the current trends, challenges and opportunities of selected digital libraries in Ethiopia. A structured questionnaire was used to get pertinent data administered to library staffs and digital library users using purposive and convenience sampling technique respectively. The study identified that Dspace and Green Stone are used digital library platforms in most of the digital libraries in Ethiopia because of its interactive user interface, full text accessibility, and easiness for installation criteria's. The study results showed that thesis and dissertations and rare books were the most ranked items digitized for academic and research purpose. The major challenges of digital libraries in Ethiopia were found copyright issue of intellectual properties, and lack of funds to support digital libraries, incompatibility of digital library platforms for local languages, and lack of digital library plan, policy and procedures. Low speed of Internet connection and low quality of digital collections were problems while users gaining access to digital libraries. To educational, cultural, historical and governmental documents preservation and to wide document accessibility were placed the major opportunities for digital libraries in Ethiopia. Therefore digital libraries in Ethiopia should have a national digital library policy, plan, standards, and procedures for successful digital library development in the country were forwarded as recommendations.
\end{abstract}

\section{Keywords}

Challenges, Digital Library, Digital Library Staffs, Digital Library Users, Ethiopia, Opportunities, Trends

\section{INTRODUCTION}

\subsection{Background}

The success of an academic library depends not only on the information resources it owns or licenses but on the services it provides. User's expectations of libraries have increased during a period of relatively stagnant library budgets and rising costs of archival journal and electronic resources. Libraries are at the heart of research development in research universities [1].

Developing countries have traditionally faced tremendous challenges on accessing print-based publications. Moreover, print-based publications seem to be very expensive for the buying power of developing countries. In Africa, for instance, printed academic books cost too much for the majority of students in this continent [1]. In this context of asymmetric access to information, the scientific production of developing countries will keep having reduced impact. Thus, digital libraries (DLs) seem to be the great hope for these countries by providing access of resources, theoretically anywhere and anytime, as far as, a computer with Internet access is available. In order to properly benefit from the potential of these libraries, it is necessary to build digital libraries with local contents so that people in these regions can access the national resources and publications. It is also necessary to have the indispensable devices and infrastructures for accessing these and other digital libraries. Despite the great benefits of digital libraries for developing countries, they faced several challenges on building and using such libraries. Building digital library in these contexts is a great challenge and it will leads to different incompatibility and in sustainability issue [2].

While digital repositories and libraries have been around for some time, the practice of building digital repositories/libraries in Ethiopia is a recent phenomenon. This has been due to different factors. Recent interest from professionals in the area and the proliferation of free open source technologies to build and manage local resources, has led to a number of initiatives by higher education and research institutions.

Even though some universities in Ethiopia implement library automation project to support the overall managerial function of the library and digital library project to manage electronic and digital resources, we haven't seen those implemented systems have been fully functional in sustainability way.

Therefore this study tried to explore the current trends, challenges and opportunities of selected digital libraries in Ethiopia and it achieved the following specific objectives.

- To identify digital library platforms that has been implemented in Ethiopia.

- To investigate the current trends of digital libraries in Ethiopia.

- To identify the challenges in the existing digital libraries in Ethiopia.

- To find out the opportunities in the existing digital libraries in Ethiopia

\subsection{Objectives}

The main objective of the study was to explore current trends, challenges and opportunities of selected digital libraries in Ethiopia.

\section{RELATED WORKS}

Research in the domain of digital library spans several decades. There are very limited numbers of studies that attempted to explain the trends, challenges, and opportunities of digital libraries in Ethiopia. A study by [3] has conducted to explore the extent of implementation of digital library system, challenges and opportunities of three public universities in Ethiopia. The findings of the study revealed that three of the libraries were actually involved in digitization activities yet, digitization was still at its infant stage and it was being carried out in a disorganized manner without a formal 
digitization policy or plan. Another study by [4] has conducted to investigate major challenges and opportunities of building digital Libraries in academic libraries of Ethiopian higher education institutions, Addis Ababa University and Adama University. The findings reveal the participants of this study had favorable view or opinion in most issues related to the advantages of the digital library. However, most of participants in both institutions lack awareness about the digital libraries which account $68.8 \%$ on average; currently there is no policy or guiding principles to develop digitization program; there is feared of copyright issue to make the digital library collections accessible from out of the institutions; there is lacking of original document preservation mechanism; lack of adequate budget; poor speed and reliability of Internet connection; inadequate existing ICT resources; technological obsolescence of formats; lack of ICT qualified staffs in the library; library staffs resistance to transition from traditional system; and inadequate support from institutional management are amongst the major challenges in building the digital libraries. Another study by [5] has conducted on the challenges and opportunities in the digital library management and the role of librarians in digital library management. The finding of this study reveals librarian facing many challenges in managing digital collection such as rights management, bandwidth, preservation of data, but opportunities are greater for them. According to similar study conducted by [6] focused on prospects, challenges and benefits of digital library services like digitization of local content, access wide range of services and scholarly publishing among others were identified. The study highlighted funding, infrastructure and technology as challenges facing the application of digital libraries in northwest Universities and concludes that, though they are faced with numerous challenges, however, the university libraries could gradually overcome such challenges in the course of time especially through library collaboration. Finally the study recommends that the virtual library project of the Nigerian University Commission (NUC) should be well funded and managed to the digital Libraries in various Universities. Another study entitled with "A study on challenges and opportunities for academic libraries in migrating to e-resources" conducted by [7] examines the changing facets of e-resources and current practices with regard to acquisition, Selection, mode of procurement, promotion, development policy, problems and future plans. It also highlights the methods involved in acquiring e-resources and preservation strategy, also establishes that there are challenges militating against the digitization of academic libraries and concludes with the remarks that although digitization is challenge still information professionals/librarians must meet with the practical skills and the vision to implement it in a controlled and manageable fashion. According to the study by [8] describes about the indicative role of the emerging trends in information services that the librarians play in the academic libraries. Finally, it presents the vision of the new generation; the challenges facing implementation of the digital libraries and to review the problems faced by the librarians in the academic libraries in new digital era.

\section{METHODOLOGY}

\subsection{Research Method}

A quantitative cross-sectional survey research method was used to collect required information to achieve the objectives of the study.

\subsection{Population}

The population of this study was consisted of digital library staffs and digital library users from purposefully selected digital libraries in Ethiopia. The selected digital libraries were Addis Ababa University (AAU), University of Gondar (UoG), Bahir Dar University (BDU), Jimma University (JU), Haromaya University (HRU), Adama Science \& Technology University (ASTU), Hawassa University (HU), United Nation Economic Commission of Africa (UNECA), African Union (AU), Ethiopian National Archive and Library Agency (ENALA) digital libraries.

\subsection{Sampling and Data Collection Methods}

Out of 300 digital library staffs from selected digital libraries, 120 participants were selected based on stratified sampling technique. 278 digital library users were selected based on non-probability, convenience sampling technique. A wellstructured questionnaire was designed for completion by digital library staffs and digital library users.

\subsection{Data Analysis Methods}

Once the data were collected, it was analyzed with support of Statistical Package for Social Sciences (SPSS) version 20 application software tool. Particularly, this study used descriptive data analysis technique such as tables, charts, graphs, other easily understandable forms of reports, percentages and frequency distribution with respect to the specific objectives we have considered.

\section{RESULTS AND DISCUSSIONS 4.1 Digital Library Platforms}

The Digital Library Management softwares (DLMS) present an easy to use, customizable architecture to create online digital libraries. With these institutions/organizations can disseminate their research work, manuscripts, or any other digital media for preservations and world over dissemination of digital items [9].

According to [10], DSpace is a joint project of the MIT Libraries and HP labs. It is a digital asset management system that allows institutions, such as libraries to collect, archive, index, and disseminate the scholarly and intellectual efforts of a community. Written with a combination of technologies by MIT, it is primarily used to capture bibliographic information describing articles, papers, theses, and dissertations. DSpace is adaptable to different community needs. Interoperability between systems is built-in and it adheres to international standards for metadata format. Being an open source technology platform, DSpace can be customized to extend its capabilities.

From the Table 1 below, regarding the type of the digital library platforms used in the library, Dspace and Green Stone platforms are used in selected digital libraries. However, the Dspace is the popular used open source platform in most digital libraries of selected institutions. EPrint and Bepress digital library platforms are used in UNECA (United Nation Economic Commission of Africa) and African Union digital libraries respectively as second option. 
Table 1. Types of digital library platforms

\begin{tabular}{|l|l|}
\hline Platforms & Institutions \\
\hline DSpace & AAU, JU, BDU, UOG, UNECA, AU \\
\hline Greenstone & AAU, HU, ENALE, ASTU, HRU \\
\hline Bepress & AU \\
\hline Eprint & UNECA \\
\hline
\end{tabular}

According to [11] stated about popularity indicators of software are also available in these services and it helps users to identify the right candidate. The study identified the selection criteria for open source library software includes open source licenses, functional modules, have stable releases, high collaboration among developers and user community, interactive user interface, have detailed and up-to-date documentation, and easiness of Installation and maintenance of the software.

From the findings in Figure 1 below, 22\% of the respondents have mentioned that the criteria for selection of the above digital library platform was interactive user interface followed by full text accessibility of the software $18 \%$ and then $17 \%$ of the respondents considered easiness for installation and maintains.

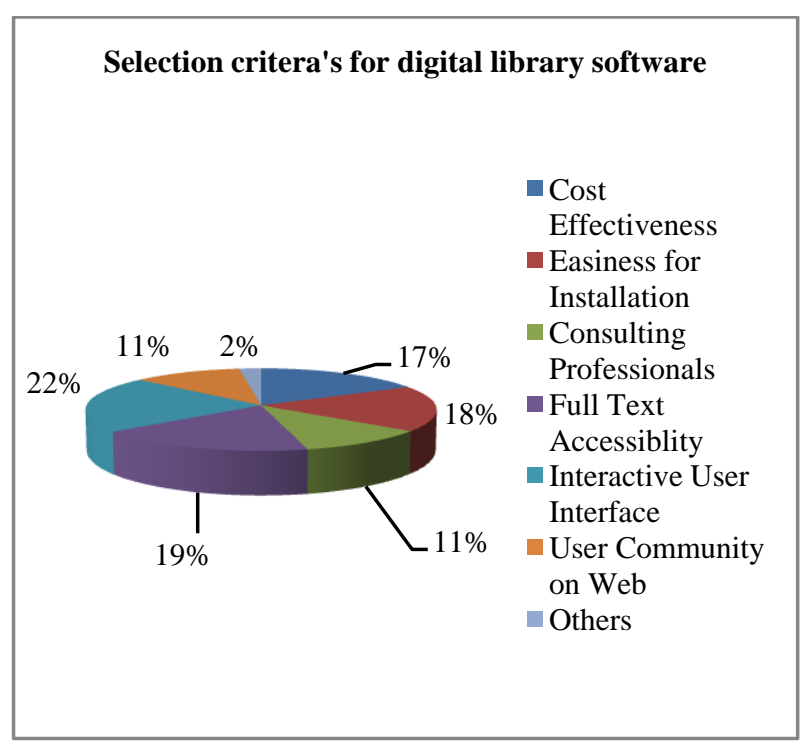

Figure 1: Selection criteria for digital library software platform

\subsection{Type of Digitized Materials}

From the findings in Figure 2 below, thesis and dissertations $(64.94 \%)$ were the most ranked item to be digitized followed by rare books $(41.55 \%)$, journals and other serials $(40.25 \%)$, course materials (29.87\%), historical documents/archives (19.88\%), reports/government publications (14.28\%), audiovisual $(14.14 \%)$, manuscripts $(12.98 \%)$, photographs (11.69\%), art work/artifacts $(10.38 \%)$, and maps/ old newspapers $(7.79 \%)$.

A study by [12] stated that digital institutional resources such as thesis, manuscripts, special monographs, research papers, or images are of very high value to academic institutions. Cooperation, automation and building of the digital library all for the enhancement of service delivery in support of teaching and research - are the principal drivers that will shape the collective future of libraries as suppliers of information to the scholarly world.

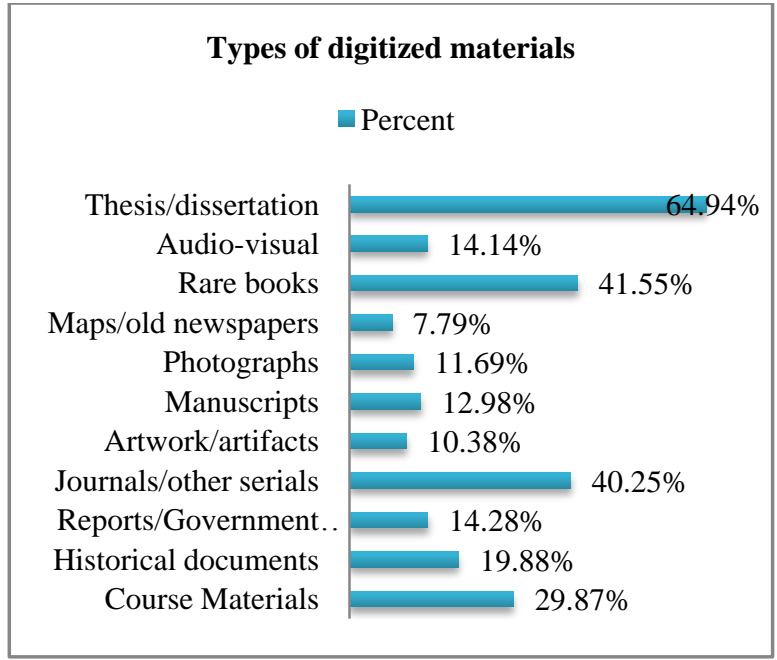

Figure 2: Types of digitized materials

According to a study [13] summarized the criteria for selection of materials for digitize collections were access, support of preservation activities, collection development, institutional and strategies benefits, research and education

From digital library staff respondents in Figure 3 below, the most important criteria to select materials for digitization were for academic and research purpose $(70.12 \%)$ and to increase the accessibility of the material $(68.83 \%)$ followed by, high demand of users $(57.14 \%)$, preservation of the materials $(37.66 \%)$, historical and cultural value $(16.88 \%)$ and the least ranked criterion was potential of commercial or revenue generation (11.68\%).

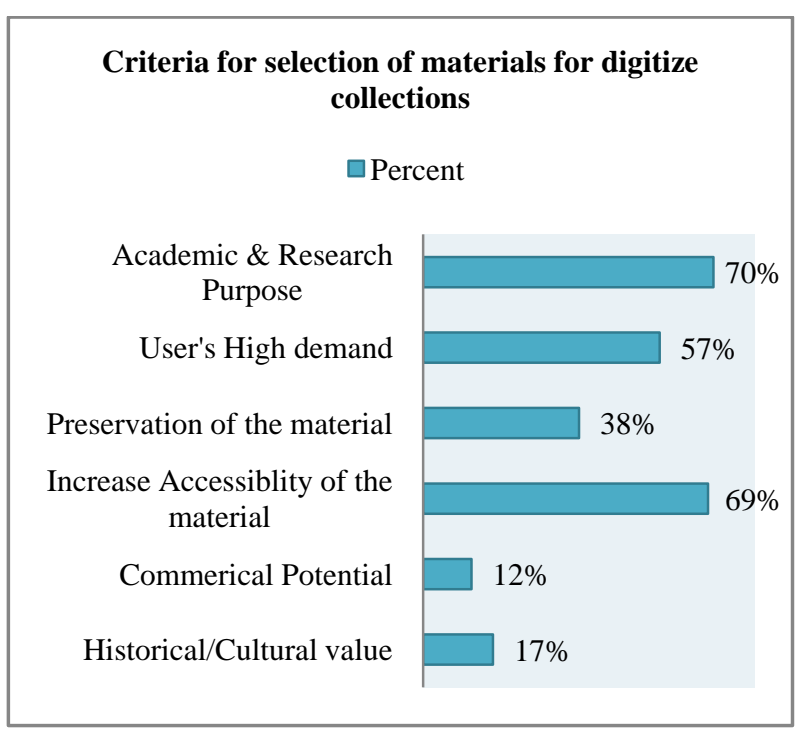

Figure 3: Criteria for selection of materials for digitize collections

\subsection{Sources of Digital Collections}

The following figure 4 show that the different sources of digital collections distribution in selected digital libraries in Ethiopia. The major sources for the digital collections was from donations (24\%) followed by researchers or instructors $(21 \%)$ and Internet $(21 \%)$, purchasing $(18 \%)$ and from other universities $(16 \%)$. 


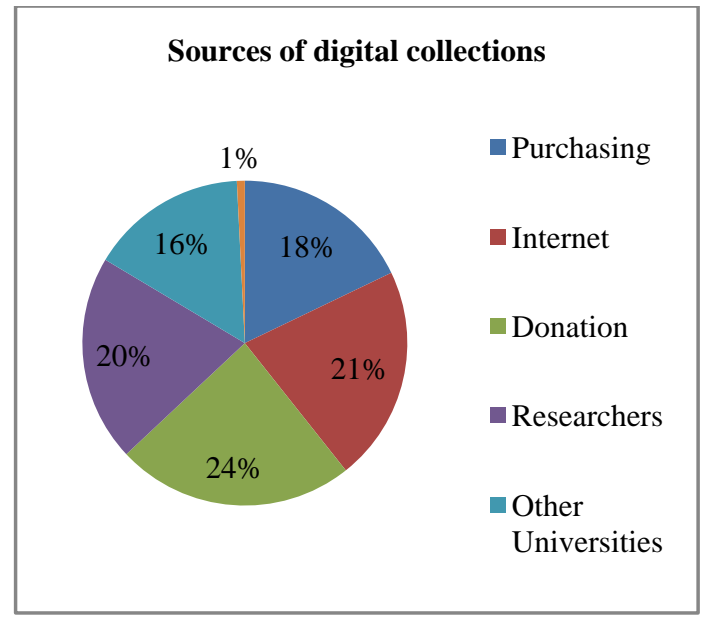

Figure 4: Sources of digital collections

Table 2. Source of funding for digitization activities

\begin{tabular}{|l|l|}
\hline Funding Organization & Percentage (\%) \\
\hline Ministry of Education & $59.3 \%$ \\
\hline Governmental \& NGO's & $37.0 \%$ \\
\hline Others & $3.0 \%$ \\
\hline Total & $\mathbf{1 0 0 . 0 \%}$ \\
\hline
\end{tabular}

From the Table 2 above, most respondents mentioned that the source of fund for digital library activities mainly from Ethiopia Ministry of Education that constitutes 59.3\% and $37.0 \%$ from Governmental Organizations Non-Governmental Organizations (NGO's).

\subsection{Partnership}

There is consideration of different aspects of internal collaboration including: collaboration within the library service; collaboration of academic libraries with faculties, other support departments, and students; convergence and super convergence; the role of liaison/subject librarians; embedded librarianship; information literacy; research support; and collaboration on library buildings and learning spaces. Coverage of external collaboration includes: local and regional collaboration; joint procurement; shared storage; joint-use libraries; work with the community; and national and international collaboration [14].

As depicted in Table 3 below, the majority (33.3\%) of selected digital libraries had partnership with International Network for the Availability of Scientific Publications (INASP) and followed by cooperation with (29.2\%) academic libraries for digital library activities. However there was no co-operation with private organization for digital library activities.

Table 3. Partnership with other organization

\begin{tabular}{|l|l|}
\hline Partner Organization & Percentage (\%) \\
\hline Ministry of Education & $4.2 \%$ \\
\hline Public Libraries & $8.3 \%$ \\
\hline Academic Libraries & $29.2 \%$ \\
\hline
\end{tabular}

\begin{tabular}{|l|l|}
\hline Special Libraries & $4.2 \%$ \\
\hline Voluntary Organization & $4.2 \%$ \\
\hline INASP & $33.3 \%$ \\
\hline Governmental \& NGO's & $12.5 \%$ \\
\hline Others & $4.2 \%$ \\
\hline Total & $\mathbf{1 0 0 . 0 \%}$ \\
\hline
\end{tabular}

\subsection{Intellectual Property and Copyright}

\section{Considerations}

A key element for digital libraries is appropriate recognition and protection of legal rights such as copyright, publicity, privacy, matters of obscenity and defamation intellectual property - protection as well as less legalistic but serious concerns associated with the ethics of sharing or providing access to folk or ethnographic materials [15].

Similar findings conducted in Ethiopian digital libraries reveals that, the majority, 18 (66.6\%) of institutions reflected triviality on intellectual property/copyright issue consideration, $3(11 \%)$ of them expressed how they were considering the issue, and the remaining $3(11 \%)$ of the institutions believed that intellectual property and copyright should belong to the institutions themselves for those records/archives in their holdings [16].

In our study most digital libraries were considered intellectual properties/copyright management during digitization. The majority, $18(66.6 \%)$ of institutions reflected triviality on intellectual property/copyright issue consideration, 3 (11\%) of them expressed how they were considering the issue.

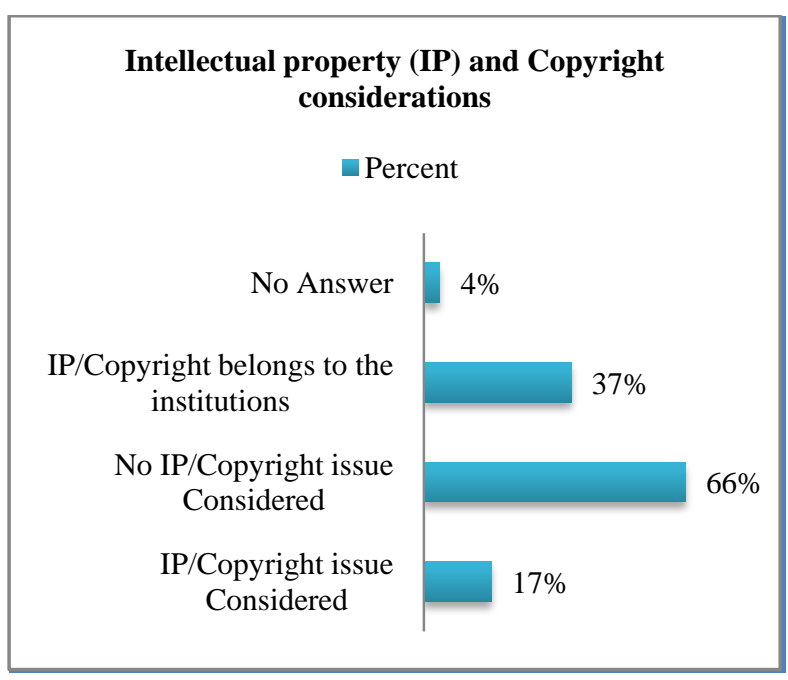

Figure 5: Intellectual property (IP) and Copyright considerations

\subsection{Response Rate of Digital Library Users}

The following table 4 shows that the frequency and percentage of respondents by their educational status. From the findings, the respondent's educational status 109 (65.5\%) were Master of Science students followed by $23(12.8 \%)$ users who have degree in Master of Art, and 16 (8.9\%) of respondents were $\mathrm{PhD}$ students. The responses demonstrate that the users of digital services and resources are postgraduate students, academicians, researchers, and undergraduate students. 
Table 4. Frequency of digital library users' respondents by their educational status

\begin{tabular}{|l|l|l|}
\hline $\begin{array}{l}\text { Education } \\
\text { Status }\end{array}$ & Frequency & $\begin{array}{l}\text { Percentage } \\
(\mathbf{\%})\end{array}$ \\
\hline BA Degree & 5 & $2.8 \%$ \\
\hline BSC Degree & 13 & $7.2 \%$ \\
\hline MA Degree & 23 & $12.8 \%$ \\
\hline MSC Student & 109 & $60.5 \%$ \\
\hline MD Degree & 3 & $1.7 \%$ \\
\hline MPH Degree & 3 & $1.7 \%$ \\
\hline PHD & 6 & $3.3 \%$ \\
\hline PHD Student & 16 & $8.9 \%$ \\
\hline Resident & 6 & $3.3 \%$ \\
\hline Total & $\mathbf{1 8 0}$ & $\mathbf{1 0 0 . 0 \%}$ \\
\hline
\end{tabular}

Figure 6 shows that the frequency and percentage of respondents according to their job category. From the findings, most of the respondents were students 125 (69.5\%) followed by $49(27.5 \%)$ academic staffs, and the remaining $6(3 \%)$ were administrative staffs.

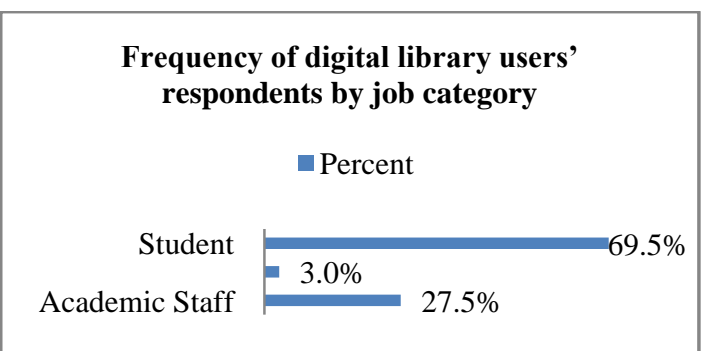

Figure 6: Frequency of digital library users' respondents by job category

\subsection{Frequency of Use of Digital Library}

According to the study conducted by [17] show the frequency at which the users were using the AVU digital library. Majority of the users $(44.8 \%)$ were using the library on weekly basis while $34.5 \%$ said that they hardly ever frequent the library.

From the findings in figure 7 shows that, $61(34 \%)$ of the respondents use the digital library at least weekly followed by $29 \%$ of the respondents use the digital library daily, and the $19 \%$ of the respondents who visit the digital library monthly. Postgraduate students make greater use of digital resources than other groups with $66 \%$ of respondents gaining access the digital library.

\section{Frequency of use of digital library}

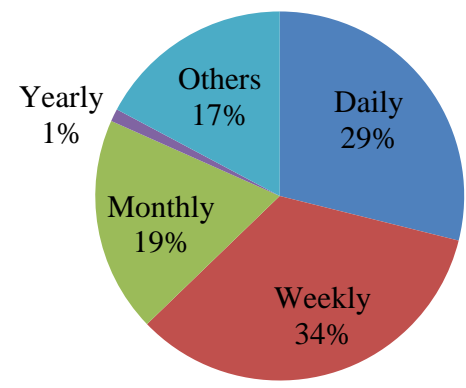

Figure 7: Frequency of Use of Digital Library

From the findings in table 4 below $95(52.8 \%)$ of the respondents use the digital libraries in the library computer room followed by $50(27.8 \%)$ of the respondents use the digital library in the computer laboratory room, and $27(15.0 \%)$ of the respondents who visit the digital libraries in their office.

Table 3. Place of accessing digital libraries

\begin{tabular}{|l|l|l|}
\hline Place & Frequency & $\begin{array}{l}\text { Percentage } \\
(\%)\end{array}$ \\
\hline $\begin{array}{l}\text { In library computer } \\
\text { room }\end{array}$ & 95 & $52.8 \%$ \\
\hline $\begin{array}{l}\text { In computer } \\
\text { laboratory room }\end{array}$ & 50 & $27.8 \%$ \\
\hline In the office & 27 & $15.0 \%$ \\
\hline In the dormitory & 3 & $1.7 \%$ \\
\hline At home & 5 & $2.8 \%$ \\
\hline Total & $\mathbf{1 8 0}$ & $\mathbf{1 0 0 . 0 \%}$ \\
\hline
\end{tabular}

\subsection{Digital Collections Accessed by Users}

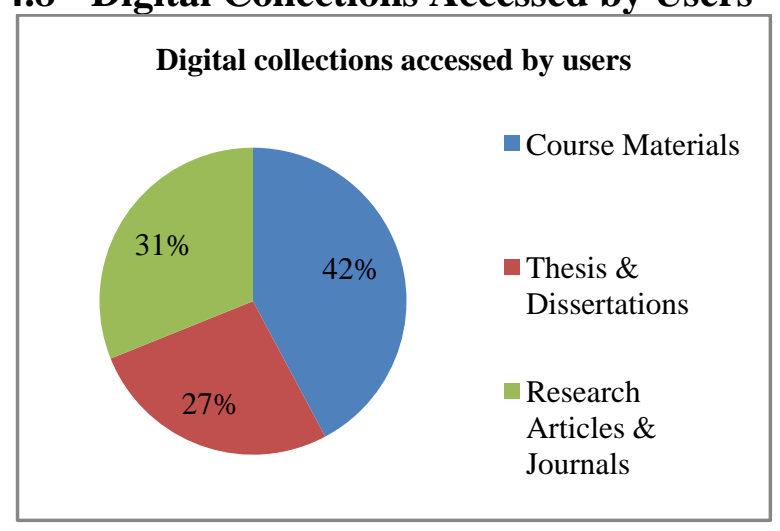

Figure 8: Types of digital collections accessed by users

From the findings in Figure 8 above, $(42 \%)$ of the respondents were accessed course materials in the digital library followed by $(31 \%)$ of the respondents were accessed research articles and journals and $(27 \%)$ of the remaining of respondents were accessed thesis and dissertations.

\subsection{Benefits of Digital Libraries}

From the findings in Figure 9 below, $(52 \%)$ of the respondents were used digital library for the benefits of access 
everywhere and anytime followed by (27\%) of the respondents were used digital library for the benefits of access rare and expensive collections and (17\%) of the respondents were used digital library for the benefits of save printing costs. The remaining $(4 \%)$ of respondents were used digital library for the other benefits.

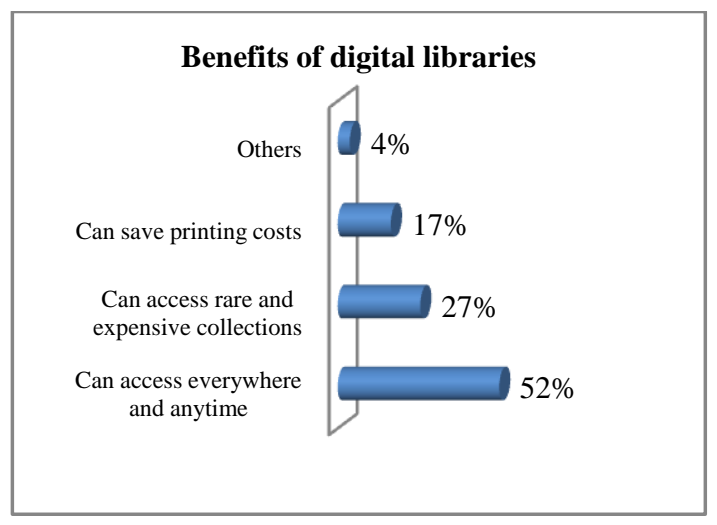

Figure 9: Benefits of digital libraries

\subsection{Problems Faced While Accessing Digital Libraries}

From the findings in Table 5 below, $85(42.7 \%)$ of the respondents were answered low speed of internet connection followed by $27(15.0 \%)$ of the respondents were answered low quality of digital collections and $53(29.4 \%)$ of the respondents were answered links are not working was a problem while gaining access to digital libraries. The remaining $15(8.3 \%)$ of respondents were encountered other problems while gaining access to digital library.

Table 5. Type of problems encountered while users accessing digital libraries

\begin{tabular}{|l|l|l|}
\hline Type of problems & Frequency & $\begin{array}{l}\text { Percentage } \\
(\%)\end{array}$ \\
\hline $\begin{array}{l}\text { Low speed of internet } \\
\text { connection }\end{array}$ & 85 & $47.2 \%$ \\
\hline $\begin{array}{l}\text { Low quality of digital } \\
\text { collections }\end{array}$ & 27 & $15.0 \%$ \\
\hline Links are not working & 53 & $29.4 \%$ \\
\hline Others & 15 & $8.3 \%$ \\
\hline Total & $\mathbf{1 8 0}$ & $\mathbf{1 0 0 . 0 \%}$ \\
\hline
\end{tabular}

\subsection{Digital Library Challenges}

A study conducted by [17] identified the challenges facing the employees and users of digital libraries at the K.U AVU center were identified to be caused by broad factors namely: management policies, infrastructure-related factors, issues related to attitude of the users towards digitalization, connectivity and reliability, training-related and system design issues.

Identifying the challenges of digital libraries in Ethiopia was one of the main research questions in this study. Accordingly, the respondents were asked to mention different challenges observed.

From the findings, most respondents remarked that lack of copyright and intellectual property right policy and lack of funds to support digital libraries followed by incompatibility of digital library platform for local languages, and lack of digital library plan, policy and procedures were the major challenges of digital libraries.

\subsection{Digital Library Opportunities}

From the findings most respondents remarked that document preservation (educational, cultural, historical, governmental and map) and to wide document accessibility of (thesis, laboratory manuals, dissertation, lecture notes, governmental policies and guidelines cultural heritage) were the major opportunities of digital libraries followed by to enhance elearning system, to enhance the collaborations between institutions, and to create opportunities for authors, researchers, and students to promote their work.

\section{CONCLUSION AND RECOMMENDATIONS}

\subsection{Conclusion}

The findings outlined that throughout this study identified the current trends, challenges and opportunities of digital libraries in Ethiopia.

Dspace and Green Stone digital library platforms are used in selected digital libraries in Ethiopia. Still, Dspace is the popular used open source platform in most digital libraries of selected institutions in Ethiopia. Interactive user interfaces, full text accessibility, and easiness for installation and maintains of the platform were the leading criteria for the selection of the digital library platforms in most of selected digital libraries in Ethiopia.

Another current trend in selected digital libraries was the type of materials being digitized and guided criteria for the selection of materials. Accordingly, the prior digitized materials in selected digital libraries was thesis and dissertations, rare books, journals and other serials, and course materials in ascending order. Academic and research purpose, wide the accessibility of the material, high demand of users, and preservation of the materials were the leading guided criteria for the selection of type of materials being digitized in selected digital libraries in Ethiopia.

The major sources for the digital collections were from donations, researchers/instructors, internet, and purchasing. Sources of funding for digital library activities were from Ministry of Education and governmental organizations \& nongovernmental organizations. Majority of the selected digital libraries had partnership with INASP () and academic libraries for digital library activities.

Despite the numerous challenges faced, the main challenges for digital libraries were lack of copyright and intellectual property right policy, lack of funds to support digital libraries, incompatibility of digital library software for local languages, and lack of digital library plan, policy and procedures.

The main opportunities for digital libraries in Ethiopia were documents preservation, to wide document accessibility, to support e-learning system, and to enhance collaborations among institutions.

\subsection{Recommendations}

The following recommendations are forwarded based on the findings of this study to improve the digital libraries in Ethiopia:

- $\quad$ There should have a national digital library policy, plan, standards, and procedures for successful digital library development in the country. 
- Digital libraries should boost their technological infrastructure, train human resources, secure funds, and develop institutional digitization plans and guidelines.

- $\quad$ Ministry of Culture and Tourism and Ministry of Education of Ethiopia should facilitate funding in particular for digital library development projects, trainings, and digital technology purchases.

- Graduates in information science department and related disciplines in the country should have the necessary skills and knowledge in digital library development and digital libraries must arrange short and long term training programs on digital library development

- $\quad$ There should have a strong national and international collaborations and consortium among digital library institutions and stakeholders for successful digital library development in the country.

- $\quad$ Digital libraries should digitize recent journals and articles collections that cover all disciplines

- $\quad$ Policy makers and mangers should give attention to increase the budget for the digital library activities and development.

- In digital libraries, the bandwidth of the internet connection must be increased in all surroundings. Faster internet access should be offered to minimize download time.

- $\quad$ Digital libraries should have an authorized and structured framework for copy and intellectual property rights in digitization activities.

\subsection{Future Research Directions}

Few public universities and national and international institutions were involved in this study. As a result, additional research is necessary on digital libraries of privet universities and colleges in the country. Further research should be done on the needs and barriers of digital library staffs and users and investigate their perceptions toward the adequacy of their libraries.

\section{ACKNOWLEDGMENTS}

This study was a result of collection of many people who have contributed directly or indirectly. So our appreciations are owned to so many people who contributed to the completion of this research. First, we would like to express our gratitude to University of Gondar for financial support and the excellent facilities to complete this research. Finally, the authors would like to thank their colleagues for their valuable comments.

\section{REFERENCES}

[1] P. Ngimwa, " An African experience in providing a digital library service: the African Virtual University example " Africa Higher Education Online, 2006.

[2] G. Chowdhury, "Digital Divide: How Can Digital Libraries Bridge the Gap," in in Proceedings of the 5th International Conference on Asian Digital Libraries: Digital Libraries: People, Knowledge, and Technology, vol. 58, Asia, 2002, pp. 258-283.

[3] K. Adane, "Building Digital Libraries in Academic Libraries of the Ethiopian Higher Education Institutions:
Challenges and Opportunities," Masters of Science In Information Science, School of Information Science, Addis Ababa University, Addis Ababa, 2013.

[4] K. Sileshi, "Implementation Status of Digital Library System in three Universities of Ethiopia: Challenges and Opportunities," Master of Science in Information Science, Department of Information Science, Haramaya University, Haramaya, 2014. [5] S. B. H. Sagar S. Kumbhar, "Digital Library Management : Challenges and Opportunities," presented at the Changing Role of Library Professionals in ICT Environment, Pachawad, 2015.

[6] Gani, Esther and Magoi, Joshua Sani, "The emergence of digital libraries services in northwest nigerian universities: challenges and prospects" (2014). Library Philosophy and Practice (e-journal). 1184.

[7] V. k. R, "A study on challenges and opportunities for academic libraries in migrating to e-resources," International Journal of Digital Library Services, vol. 6, pp. 85-94.

[8] S. G.T, "Impact of digital era on academic libraries: it's play with library professionals," International Journal of Library \& Information Science (IJLIS), vol. 6, pp. 1-7, July-August 2017.

[9] Srinagar, Kashmir, Humma, "A study on the open source digital library software: Special reference to DSpace, EPrints and Greenstone," International Journal of Computers and Applications vol. 59, pp. 1-9, December, 2012.

[10] Madalli, D. P. (2003). A digital library of library and information science using DSpace.

[11] Kumar, V. "Selection and Management of Open Source Software in Libraries," Annuals of Information Studies, vol. 59, pp. 223-230, 2012.

[12] R. Carr, "The future of libraries and collection," Keynote Address to the Fiesole Collection Development Retreat, Oxford, 20 July, 2000.

[13] U. Otubelu Blessing Nnenna, Leonard Emenike, "Digitization of Library Resources in Academic Libraries: Challenges and Implication " IOSR Journal of Mobile Computing \& Application (IOSR-JMCA), vol. 2, pp. 35-40, MAy-June 2015.

[14] J. Atkinson, "Collaboration and Academic Libraries: An Overview and Literature Review," in Collaboration and the Academic Library, J. Atkinson, Ed., ed: Elsevier Ltd, 2018, pp. 11-33.

[15]Stueart, Robert D. and Moran, B., Library and Information Centre Management Englewood: Libraries Unlimited, 1997.

[16] Getachew Bayissa, Girum Ketem, Yitagessu Birhanu, "Status of digitization process in selected institutions of ethiopia: A baseline stakeholders' analysis survey report," Ethiopian Journal of Education and Science, vol. 5, pp. 1-18, 2010.

[17] Lynette Karimi Ringeera, "A Survey of The Challenges Facing The Use of Digital Libraries in Kenya: A Case Study of Kenyatta University Avu Library," Master of Business Administration (Mba) Degree, Business Administration, UNIVERSITY OF NAIROBI, NAIROBI, September, 2007 